\title{
CAN ARTIFICIAL NEURAL NETWORK SYSTEMS BE USED FOR FORECASTING APHID FLIGHT PATTERNS?
}

\author{
G. LANKIN ${ }^{1}$, S.P. WORNER ${ }^{1}$, S. SAMARASINGHE ${ }^{2}$ and D.A.J. \\ TEULON $^{3}$ \\ ${ }^{1}$ Soil, Plant and Ecological Sciences Division, P.O. Box 84, Lincoln University, \\ Canterbury \\ ${ }^{2}$ Environmental Management and Design Division, P.O. Box 84, Lincoln \\ University, Canterbury \\ ${ }^{3}$ New Zealand Institute for Crop \& Food Research Limited, Private Bag 4704, \\ Christchurch \\ Corresponding author: lankig@lincoln.ac.nz
}

\begin{abstract}
In Canterbury, the cereal aphid (Rhopalosiphum padi) has a bi-modal annual flight pattern with peaks in autumn and late spring. The autumn peak coincides with the migration of aphids into autumn and winter sown wheat. The timing, magnitude and duration of flights vary dramatically from year to year and can have important implications for the management of this aphid in cereals. Twenty years of climatic and aphid flight data were used to train a neural network to obtain a model to predict the date and size of aphid migrations in cereal crops in Canterbury, New Zealand. The model provided an exceptional fit to the ten years of training data but gave disappointingly poor prediction for the eight years of validation data. Possible reasons for poor prediction of validation data are given and suggestions are made concerning future developments.
\end{abstract}

Keywords: Rhopalosiphum padi, BYDV, population dynamics, neural networks, backpropagation algorithm.

\section{INTRODUCTION}

One of the greatest causes of yield loss in New Zealand wheat crops is barley yellow dwarf virus (BYDV) which is vectored by several aphid species. The most important of these is Rhopalosiphum padi (Smith \& Wright 1964). In Canterbury, this aphid typically has a bi-modal seasonal flight pattern, with distinct peaks in autumn (April, May) and late spring (October) (Teulon et al. 1999).

A programme to forecast the incidence of BYDV in winter and autumn sown cereal crops, based on the flight patterns of aphid vectors caught in $7.5 \mathrm{~m}$ high suction traps during the growing season, has been developed by Crop \& Food Research (Teulon et al. 1999). However, information on expected aphid flight patterns prior to their initiation would be of considerable benefit to growers in their pest management activities, especially in relation to the need for insecticide treatment of seed for aphid control at the beginning of the season. The non-linear and complex nature of the population dynamics of insects makes it very difficult to predict future population densities using traditional methods. However, artificial neural networks (ANN) are an aspect of computational intelligence research that has recently shown efficacy in describing non-linear biological systems (Chon et al. 2000; De Wolf \& Francl 1997; Zaidi et al. 1999).

ANN are attempts to mimic the computational processes of the brain that consist of a number of interconnected processing elements or "neurons" (Pham \& Liu 1995). Usually, at one end of the network, data are fed in and at the other end, the network produces outputs. In between, there are layers of "neurons" that may or may not fire, depending on their current state, their inputs from earlier layers and their own properties (Brown \& Rothery 1993). 
Backpropagation networks, in particular, can be trained to detect structure in timeseries and use that structure to learn to predict future events from historical data (Kutza 1996). During the training process the input variables are presented in a certain order. After each presentation, the network interconnections (weights) are adjusted using a specified algorithm to improve the network prediction for the input presented. After sufficient presentations the network is usually trained, and can be used for predicting new cases (Brown \& Rothery 1993). Training consists of minimising the mean square error between the actual output and the desired output, and stops when the network meets a specified stopping criterion (Chon et al. 2000). Designing a neural network involves much iteration. There are no general rules for the process nor is there guidance in the literature for those applying neural networks to ecological time series.

Climate variables and density dependent factors are well known to influence insect population dynamics (both development and migration). Many other biological variables that influence insect populations are also affected by these variables (Worner 1998). Climate data has been used successfully over many years in phenological models to predict timing of insect life cycle events, but traditional population models that predict insect population densities have been less successful (Worner 1998). The objective of this study was to develop a model using neural networks, capable of predicting the number of aphids and timing of aphid flights in Lincoln, Canterbury, using historical climatic and aphid flight data.

\section{MATERIAL AND METHODS}

Aphid flight activity was monitored at $7.5 \mathrm{~m}$ above ground with a suction trap at Lincoln, Canterbury, from 1981 to 2000 . Weekly aphid flight activity for $R$. padi was collated for this period (Farrell \& Stufkens 1992; Teulon et al. 1999).

Daily climate data was also recorded at the Canterbury Agricultural Research Centre at Lincoln, Canterbury, over the same period. The data included: rainfall $(\mathrm{mm})$; maximum, minimum and mean air temperature $\left({ }^{\circ} \mathrm{C}\right)$; grass minimum temperature $\left({ }^{\circ} \mathrm{C}\right)$; solar radiation $\left(\mathrm{MJ} / \mathrm{m}^{2}\right)$; wind run (km/day); vapour pressure $(\mathrm{hPa})$; Penman potential evaporation $(\mathrm{mm})$; potential deficit (accumulated excess of Penman over rainfall); cumulative degree days (over a threshold of $0^{\circ} \mathrm{C}$ ) $\left({ }^{\circ} \mathrm{C}\right)$; and soil temperature at 5, 10, 20, 30 and $100 \mathrm{~cm}$ below ground $\left({ }^{\circ} \mathrm{C}\right)$. Because aphid counts were made weekly, all the climatic parameters were averaged weekly to align the data.

The data were first analysed graphically using combinations of inputs and outputs to determine possible significant relationships between the input variables. The software used for the development of the backpropagation network was Neuroshell II (release 4.0). Approximately 35 combinations of input data, using different time spans (to account for density dependent effects), algorithm architecture, "neuron" number, stopping criteria, and transfer functions were evaluated for their influence on forecast performance. The data set was split into two periods or subsets. The training set consisted of 10 consecutive years of data for model development and the validation set had approximately 8 consecutive years for model validation (Table 1). The stopping criterion used was an average minimum error of 0.0002 for the training set.

\section{RESULTS}

The best model gave an $\mathrm{R}^{2}$ of 0.9546 for the training set (Fig. 1). The combination of input parameters that gave the best fit of the network to the observed data was average weekly rainfall, mean air temperature, grass minimum temperature, solar radiation, wind run, vapour pressure, Penman potential evaporation, potential deficit, cumulative degree days, soil temperature at $100 \mathrm{~cm}$ below ground and weekly aphid counts lagged by six months (Table 1).

The model describes the observed data of the training set exceptionally well, especially the height and timing of peak flights. The number of aphids predicted by the network were well matched to that of the observed data, giving a high correlation $(r=0.98)$ and a slope close to unity (slope $=0.94)($ Fig. 2$)$. 


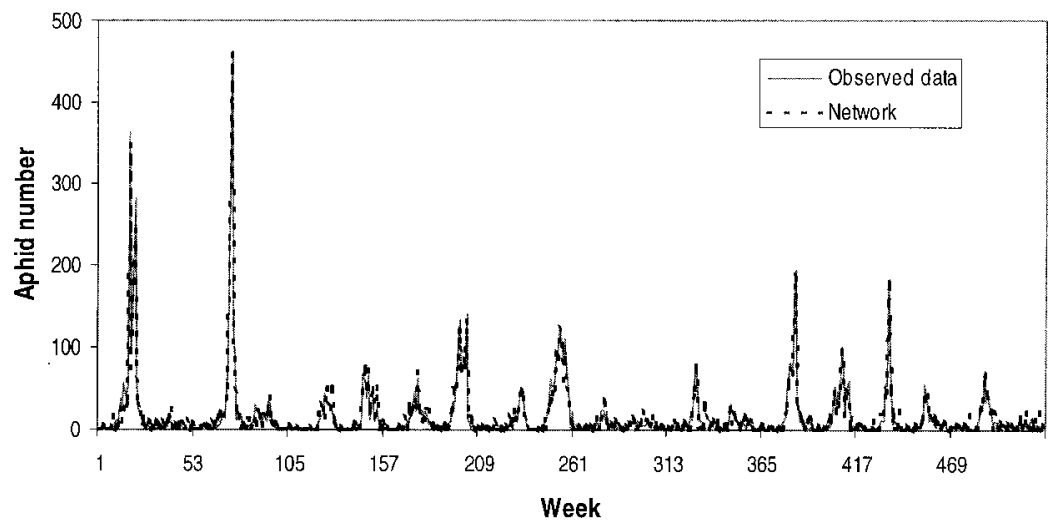

FIGURE 1: Plot of aphid numbers and network predictions for the training data set.

TABLE 1: Predetermined periods for training and validation data set, including their corresponding inputs and output.

\begin{tabular}{llcccc}
\hline & & \multicolumn{2}{c}{ Training set } & \multicolumn{2}{c}{ Validation set } \\
\cline { 3 - 6 } & & from week & to week & from week & to week \\
\hline \multirow{2}{*}{ Inputs } & Climatic data & $27 / 1981$ & $26 / 1991$ & $27 / 1991$ & $50 / 1999$ \\
\cline { 2 - 5 } Output & Number of aphids & $01 / 1982$ & $52 / 1991$ & $01 / 1992$ & $24 / 2000$ \\
& Number of aphids & $27 / 1982$ & $26 / 1992$ & $27 / 1992$ & $51 / 2000$ \\
\hline
\end{tabular}

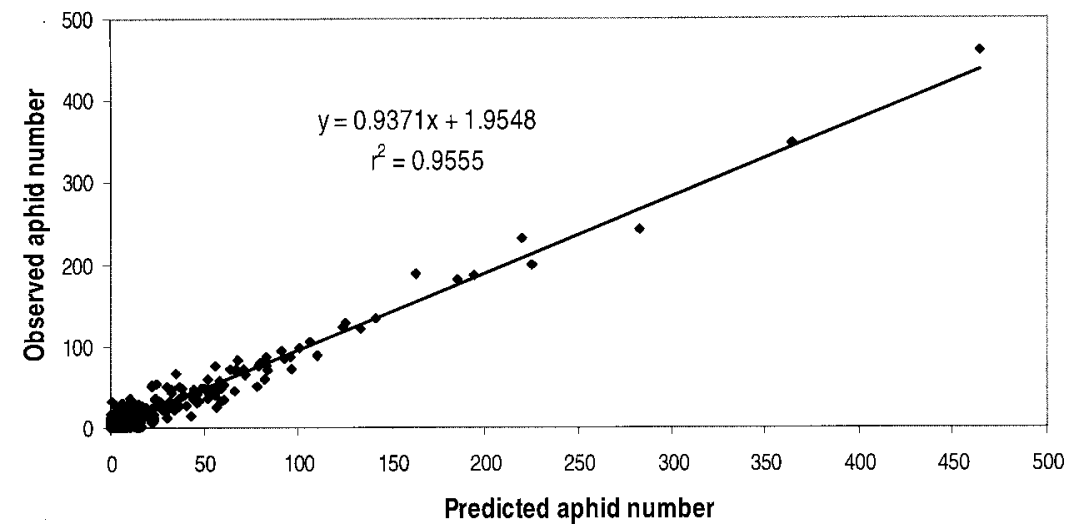

FIGURE 2: Regression analysis showing the relationship between network and observed data for aphid numbers in the training set. 
Figure 3 shows the performance of the network predicting the test and validation sets combined. Week 521 indicates the end of the training set and the beginning of validation. The accuracy of prediction noticeably changes when the network reaches the validation data set giving reasonably good prediction of the timing of major flights but disappointingly poor prediction of aphid numbers. The correlation between the observed and predicted aphid numbers was poor $(r=0.14)$.

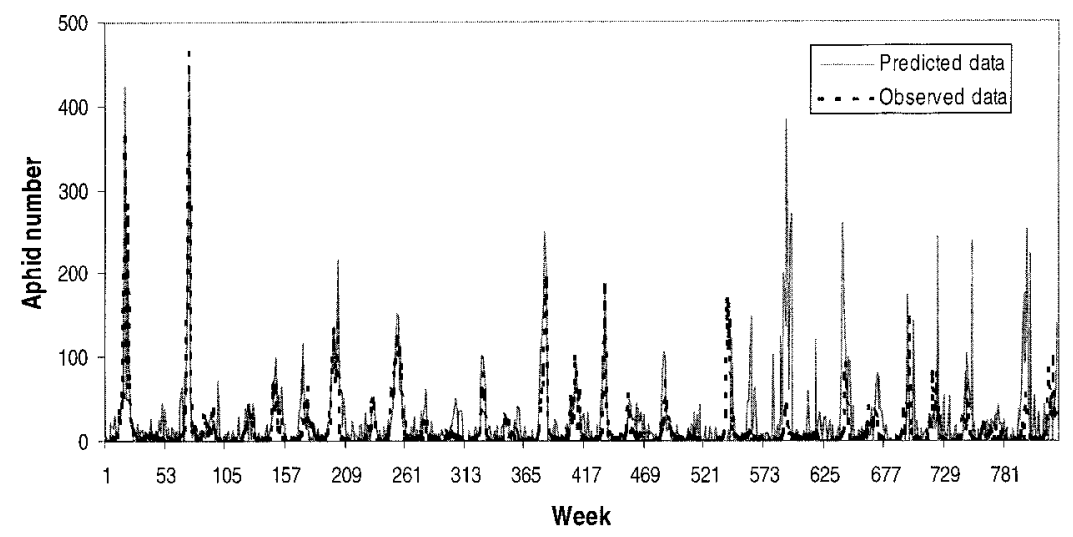

FIGURE 3: Plot of predicted and observed aphid numbers for training and validation data sets combined.

\section{DISCUSSION}

Other studies using neural networks have shown that these systems have good potential for forecasting biological phenomena. De Wolf \& Francl (1996), working with wheat tan spot, developed a model capable of correctly predicting $87 \%$ of the events in a validation set. Chon et al. (2000), developed backpropagation networks for predicting population densities of the pine needle gall midge, with a correlation of 0.93 . While the timing of peaks was well matched, Chon et al. observed substantial differences in the amplitude of the peaks, as in this study.

The low level of prediction of the validation data in the present study could be due to the sudden and sharp changes in numbers of aphids in the data set used to train the network. The climatic data follow a gradual seasonal pattern that repeats every year. The aphid counts, on the other hand, while they show a certain pattern in terms of the overall shape and timing of the bi-seasonal peaks, can change abruptly from one week to the next. In other words the data has much stochastic noise, making it difficult for the network to predict the exact numbers. Another possibility for poor prediction of the validation set is that the network has been subjected to overfitting, which De Wolf \& Francl (1996) point out is a risk in ANN model development. This suggests that the training set of data was "memorized" by the network, so that it was unable to predict new data (Klerfors 1998). ANN models also share a limitation with all empirical prediction methods in that prediction accuracy is often only valid within the range of the independent variables on which the models are developed and cannot be generalised to new data (Klerfors 1998). In this study, the independent variables of the validation set were well within the ranges to which the network had been previously exposed. Despite the poor prediction of the validation set, we believe that the neural network approach has considerable potential to improve prediction of complex nonlinear biological events such as aphid migration. 
To avoid overfitting, possible modifications are to change the stopping criteria and set a lower number of processing elements within the network. Other modifications to improve prediction could consist of smoothing the aphid count data to eliminate noise or to convert the data to ranges, categories or thresholds. In addition, to avoid the network learning false trends, the autumn and late spring peaks (the input variables) could be separated and the years arranged randomly, not in the chronological order that was done for this study.

\section{REFERENCES}

Brown, D.; Rothery, P. 1993: Models in biology: Mathematics, statistics and computing. John Wiley and Sons Ltd., England. 688 p.

Chon, T.; Park, Y.; Kim, J.; Lee, B.; Chung, Y.; Kim, Y. 2000: Use of artificial neural network to predict population dynamics of the forest-pest pine gall midge (Diptera:Cecidomyiidae). Environ. Entomol. 29: 1208-1215.

De Wolf, E.D.; Francl, L.J. 1997: Neural networks that distinguish infection periods of wheat tan spot in an outdoor environment. Phytopath. 87: 83-87.

Farrell, J.A.; Stufkens, M.W. 1992: Cereal aphid flights and barley yellow dwarf virus infection of cereals in Canterbury, New Zealand. N.Z. J. Crop Hort. Sci. 20: 407412.

Klerfors, D. 1998: Artificial neural networks. What are they? How do they work? In what areas are they used? http://hem.hj.se/ de96klda/NeuralNetworks.htm (04/10/01).

Kutza, K. 1996: Neural networks at your fingertips. Wysiwyg://12/http:/ www.geocities.com/CapeCanaveral/1624/ (04/10/01).

Pham, D.T.; Liu, X. 1995: Neural networks for identification, prediction and control. Springer-Verlag London Limited, Great Britain. 238 p.

Smith, H.; Wright, G. 1964: Barley yellow dwarf virus on wheat in New Zealand. N.Z. Wheat Review 9: 60-79.

Teulon, D.; Stufkens, M.; Nicol, D.; Coup, D.; Hartcourt, S. 1999: Forecasting barley yellow dwarf virus in autumn-sown cereals in 1998. Proc. 52nd N.Z. Plant Prot. Conf.: 187-191.

Worner, S.P. 1998: Some problems and approaches to modelling insect phenology. In: Baumgärtner, J.; Brandmayr, P.; Manly, B.J.F. ed. Population and community ecology for insect management and conservation. A.A. Balkena, Netherlands. Pp. 89-98.

Zaidi, M.A.; Murase, H.; Honami, N. 1999: Neural network for the evaluation of lettuce plant growth. J. Agric. Eng. Res. 74: 273-242. 